\title{
Marketing Strategies of Enterprise News Planning
}

\author{
Yong Zhang \\ School of Economics \& Management, Sichuan University of Science and Engineering, \\ Zigong, 643000, China
}

Keywords: enterprise news, planning, principles, methods

\begin{abstract}
With the improvement of economic development and scientific level in China, competition among enterprises becomes increasingly fierce. Under the influence of this market economy environment, enterprises have to be more concerned about brand image and publicity planning means than before. Therefore, marketing of enterprise news planning has direct influence on the survival and development of enterprises. This paper mainly describes the concept, development, principles and notices of enterprise news planning, and hopefully analysis of this paper can help enterprises do better in news planning.

Today, social development has been inseparable from important science and technology. Similarly, enterprises cannot be separated from mass media at the construction and development stage, and particularly enterprises have to establish their own brand images by various methods because of increasingly fierce competition among enterprises under market economy environment. Advertising is the most common method, but is not omnipotent. For example, CCTV brand kings "Qinchi” and "Aiduo" invested a huge amount of money in advertising to establish their own brand images, but finally suffered a complete loss, so that many enterprises often stepped back in front of huge advertising costs. Then, enterprise news planning means emerge, and such means can be used to establish enterprise brand images, have advantages compared with advertising in terms of communication, and have been gradually getting increasingly more concern and attention of enterprises currently.
\end{abstract}

\section{Concept and connotation of enterprise news planning}

In recent years, enterprise news planning develops rapidly and strikingly, and is used by increasingly more enterprises. For enterprises, means to establish brand images mainly include advertising and news media, and the latter has the highest input-output ratio in comparison. Staffs of Cultural Department of Famous brand Haier say that Haier does not invest a lot in advertising, and one third of its wide popularity comes from publicity of news planning. Advertising relies on design creativity and huge capital investment, and would not have any publicity effects if it is not played frequently enough, and then huge advertising fund is needed in order to establish a stable image of enterprise brand. Compared with advertising, news planning integrates resources of enterprises by news media, and makes news about enterprises by taking advantage of events earnestly concerned by the society to achieve effects of publicity and communication of enterprise brands just like advertising. Besides, news planning saves more costs than advertising, and maybe can reach the same publicity effects with RMB several hundred even if such effects can only be achieved with RMB several ten thousand by advertising. Therefore, enterprise news planning plays an important role in publicizing enterprise brands and establishing corporate images.

1.1 Concept of enterprise news planning

Enterprise news planning is mainly the combination of news and planning. From the perspective of enterprise management, planning is not only a management technology, but also a type of thought and skill, while news planning is innovative publicity based on management and marketing aiming at enterprise product marketing, enterprise brand publicity, establishment of corporate image and improvement of competitive advantages etc, and is not of the same nature with general media news reports, but should also follow release principles of authenticity and credibility. The difference is that media report by seeking events that have happened. In contrast, enterprises plan and make news according to their needs, attract attention of media, and let journalists report objectively and 
fairly, and move consumers with true news and sincere feelings, to publicize corporate images. That is to say, enterprise news planning is actually that enterprise operators or internal planning staffs carry out a series of data analysis according to marketing demands and news rules, integrate corporate advantageous resources, and make news by hot events through news media, to establish corporate and product images, corporate and product brands, create good external development environment, create product markets, develop consumer demands and thus achieve product sales. Thus, enterprise news planning is actually a marketing method and thus wins concern and attention of increasingly more enterprises.

1.2 Characteristics of enterprise news planning

The similarity of enterprise news planning and media news report is that both of them follow principles of authenticity and credibility. However, as enterprise news planning is completed with planning of professionals and belongs to artificial news, it has also the following distinct characteristics:

\subsubsection{Profitability of news planning}

Enterprises are economic organizations aiming at making profits. Thus, all planned activities of enterprises including enterprise news planning are based on making profits. Enterprise planning staffs make news reports with hot spots of enterprises for consumers according to their marketing demands, in order to show positive corporate images, develop broader economic markets, and promote consumer behaviors. Therefore, news planning is an enterprise behavior that makes profits for enterprises.

\subsubsection{Innovativeness of news planning}

The similarity of news planning and advertising planning is innovativeness. News that is not novel enough could not attract consumers' attention, and thus innovativeness of news planning is very important. If enterprise news planning fails, the reason is lack of innovativeness and unique conception and such news planning is just a common planning scheme to a great extent. Thus, to ensure innovativeness of news planning, planning staffs should have unique minds and innovation ability, such as familiarity with unique ways of thinking like reverse thinking and comparative thinking etc, so as to discover unexpected hot news. Thus, only unique, novel and distinctive news planning could show unique news charm and superior publicity effects.

\subsubsection{Advancement of news planning}

Before news reports, enterprises would often predict news planning schemes to be implemented in advance, to completely ensure that news planning schemes are unique and are not the same with or similar to those of other enterprises. Attractive place of news planning is its unique innovation, as publicity effects would be greatly reduced if other enterprises have planning with slight differences. Therefore, to achieve advancement in news planning, planning staffs shall have good advanced thinking and scientific prediction ability. Otherwise, consumers' attention will be lost.

1.3 Goals of enterprise news planning

Enterprise news planning is a publicity means invented to achieve enterprise marketing services. Through integral analysis, enterprise news planning has mainly the following goals:

\subsubsection{Brand goal}

Brand image and publicity have been the focus of enterprises. News planning, as a marketing approach, plays a certain role in promoting and publicizing enterprise brand. For example, Zhang Ruimin of Haier broke refrigerators. This practice itself could not promote product sales, but establishes a serious, responsible and glorious image for enterprises and wins trust of consumers and partners. Therefore, news planning plays a huge role that cannot be ignored in enterprise brand publicity, and enterprises could achieve better sensational effects than advertising if they could seize favorable events to enhance brands combined with news planning.

\subsubsection{Sales goal}

Sales goal refers that enterprises establish brand images by media through news planning, attract consumers' attention, and thus achieve the goal of product sales. Usually, enterprises would inform the society in the way of news report that they are developing new products, in order to advertise before coming into the market to attract consumers' wide concern and open sales channels for 
products to be on the market later. For example, the first swordsmen film "Hero" of director Zhang Yimou in 2003 had been widely known before release, attracted wide attention of all walks of life, and gained box-office miracle of Chinese films immediately after release. This shows sales goal of news planning.

\subsubsection{Competitive goal}

Today, competition among enterprises becomes increasingly fierce, as marketing is often accompanied by competition. As an enterprise marketing means, news planning certainly has competitive goals. The main performance is that enterprises carry out targeted news planning towards competitors to achieve the purpose of competition. Competition never ends, and thus is an endless game for enterprises, and only enterprises which dare to compete and struggle can survive and develop.

\section{Strategies of enterprise news planning}

\subsection{Implementation steps of enterprise news planning}

From the perspective of implementation, news planning requires planning staffs to collect and analyze all-round enterprise information and control the relationship between enterprises and news media. Therefore, there are mainly the following implementation steps:

\subsubsection{Market analysis}

Market analysis is the foundation of enterprise news planning. Firstly, enterprises should have an in-depth understanding of industry and relevant situation of planning objects, report opinions of enterprise leaders to the public and do research.

\subsubsection{Determination of publicity goals}

Enterprise news planning shall focus on determination of publicity scope and target groups, in order to carry out publicity smoothly and establish good corporate images. Arouse demands of target groups through news planning schemes and lead consumers to buy products.

\subsubsection{Planning of "hot news"}

Enterprises shall integrate all relevant materials, find news from their products, special people, successful experience, industry dynamics and social activities, and learn ways to "seize opportunities" and "build up the momentum". In terms of planning news, enterprises shall be good at event marketing, i.e. use or make events with news value by mastering the law of news, spread events through specific operation and thus reach the goal of dissemination.

\subsubsection{Media selection}

News planning is to evaluate enterprise brands from a fair perspective, to gain communication effects and thus affect the public. Therefore, news planning often chooses media according to product characteristics and publicity goals. Planning staffs shall use strongly influential mass media to spread favorable and positive reports of enterprises, and consider about regional and national gaps in terms of selection to achieve stronger publicity.

\subsubsection{Measurement of planning effects}

Measurement of planning effects is to measure whether news planning activities achieve established goals, aiming at providing reference data and experience for future news planning activities by recording planning effects. Main measurement method is evaluation of news broadcast quality and market response. News media broadcast quality mainly involves length of article, word count, broadcast time length, published layout, broadcast time period, the appearance of names of enterprises and products, and introduction of product performance etc; and market response includes two aspects, namely sales performance and improved publicity of enterprises or products.

2.2 Operation strategies of enterprise news planning

Enterprise news planning is a strongly operational and skilled work, and thus has mainly the following strategies:

\subsubsection{Establish a planning team with strength}

The quality of enterprise news planning schemes comes from personal qualities and working ability of planning staffs. Therefore, enterprises shall establish an elite team with strength, strengthen business training for planning staffs, and practice their news writing ability, innovation 
ability and marketing management knowledge. An excellent enterprise news planning staff shall have news writing knowledge and knowledge about enterprise management and planning activities, and conceive planning schemes that are beneficial for enterprise marketing in terms of enterprise demands. Only with all aspects of knowledge, can a planning team with strength be established.

\subsubsection{Win trust of media and consumers with integrity}

Enterprise news planning should be true and credible, and news media report enterprises positively from an objective perspective. If enterprises' news planning is not true, trust of media and consumers will be seriously affected, and then news planning becomes insignificant. Therefore, news planning shall be based on realistic planning attitude, and shall not pursue brand awareness and sensational effects blindly, but to win trust of media and consumers with integrity.

2.2.3 Insist on innovation unremittingly in the long run

Today, news planning has been concerned and used by enterprises, and news of an enterprise could only be always concerned by the public by long-term and continuous broadcast. Therefore, to establish everlasting brand images, planning staffs shall constantly keep news innovative and treat innovation as a job requirement. Only in this way, can enterprises be constantly concerned by media and the public, and only by insisting on innovative publicity, can they establish good reputation in the mind of the public.

\subsubsection{Master planning time}

Competition among enterprises often requires mastery of time, i.e. "quickness”, as enterprises could only win by getting ahead of others, such as coming up with creativity that others have not thought of in advance and doing things that others haven't started. It is also true for news planning. Enterprises should have consciousness of taking the lead, as media communication effects would be affected by social environment. By seizing the chance when there are attractive major social events and making use of this chance, enterprises could get free publicity chance. Therefore, it is very important to master good time.

\section{Conclusions}

Nowadays, enterprises have increasingly fierce competition, and should increase efforts in enterprise brand publicity to lead consumers to buy, in order to stand out from competition and maintain good economic benefits. Enterprise news planning could not only achieve brand publicity and establish corporate images, but also realize the goal of marketing through publicity of news media. Therefore, enterprises shall attach importance to news planning, master each planning link completely, follow principles of news planning, and ensure authenticity and credibility. Only in this way, can enterprises establish stable brand images for future prosperous development.

\section{References:}

[1] Sun Shanhe. Enterprise News Planning and Brand Operation [J]. Journalism Lover. 2010 (11).

[2] Shang Yingru. On Enterprise News Planning [J]. Journalism Knowledge. 2011 (12).

[3] Ding Yi. News Marketing: Let Media Work for You [J]. Enterprise Science and Technology \& Development. 2010 (15).

[4] Shangguan Xuming. Probing into Enterprise News Marketing Planning [J]. Special Zone Economy. 2009 (11).

[5] Fan Zhengli. How Enterprise News Comes into Sight of Media [J]. Today’s Massmedia. 2008 (01). 